\title{
A EMERSÃO DO CORPO VIVO ATRAVÉS DA CONSCIÊNCIA: UMA ECOLOGIZAÇÃO DO CORPO
}

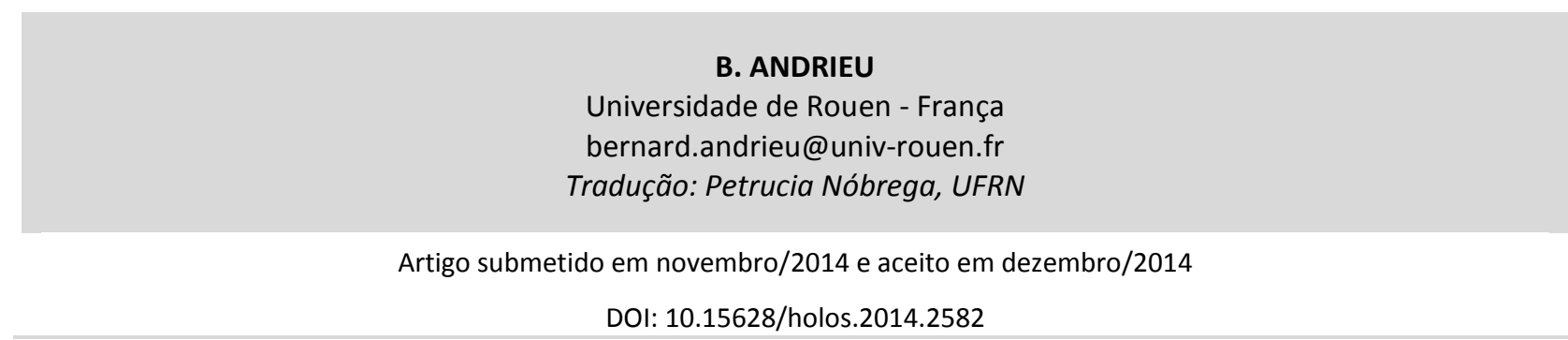

\section{RESUMO}

O corpo vivo se imerge nos espaços. Meio e corpo inserindo-se inteiramente nos espaços no curso da imersão sem que uma personalidade dirija conscientemente esses movimentos. Convém evitar aqui um vitalismo finalista que atribuiria uma intencionalidade representacional do corpo vivo. Uma ecologia pré-motriz é sentida imediatamente pelo corpo na relação com o mundo. O corpo vivo age em pessoa e não como uma pessoa, sem intermediário, menos por uma reflexividade consciente que por um despertar e uma ativação. $\mathrm{Na}$ imersão, o corpo vivo invade inteiramente a sensibilidade sem que o sujeito consiga ser extraído pela reflexão: a intensidade é tão forte que ela transborda os quadros estesiológicos habituais, emergindo na consciência do corpo vivido.

PALAVRAS-CHAVE: corpo, emersão, sensação.

\section{THE EMERSION OF THE LIVING BODY THROUGH THE CONSCIENCE: AN ECOLOGIZATION OF THE BODY}

\begin{abstract}
The alive body dives into spaces, circles and up to the imsertion ( by fitting completely in the process of the dumping) without that a personality steers consciously theses movements. It is advisable to avoid here a finalist vitalism which would attribuate a reprentationnal intentionality to the alive body. A pre-diving ecology is however smelt at once by the body in its relation to the world. The alive body acs personallu, and not as a person,
\end{abstract}

without intermediary, less by an conscious reflexivity than by an awakening and an activation. In the imsertion, the alive body invades completely the sensibility without that the subject succeeds in extracting by the reflection : the intensity is so strong as it extends beyond the estehsiologic executivesusual and the emersion in the live consciouness.

KEYWORDS: body, emersion, sensation. 


\section{INTRODUÇÃO}

Traduzindo com Christine Lafon e François Félix, publicando L'autocérébroscopie de Herbert Feigl (Feigl, 2002; Andrieu, 2006), os inéditos sobre Quel physicalisme? de Rudolf Carnap (2011) (Andrieu; Felix, 2013), a tese de Karl Popper (2012) e nossos trabalhos sobre o cérebro psicológico (Andrieu, 1999), descobrimos o atraso da consciência sobre a atividade do cérebro vivo. As neurociências in vivo demonstraram que a partir de 40 milésimos de segundo o corpo vivo poderia ativar em seu cérebro uma assinatura da presença do mundo. A ativação está na atividade do cérebro vivo que produz respostas à ecologização do corpo que pode ser registrada pela imagem in vivo (Dehaene, 2014) e por outros captores de medida. O tratamento das informações pelo cérebro vivo é mais vasto que a seleção atentiva da consciência. A atividade de ecologização do corpo vivo aporta uma regulação pelo cérebro dessas informações em função das necessidades de ação: "nosso cérebro reconhece e categoriza inconscientemente" (Dehaene, 2014, 75).

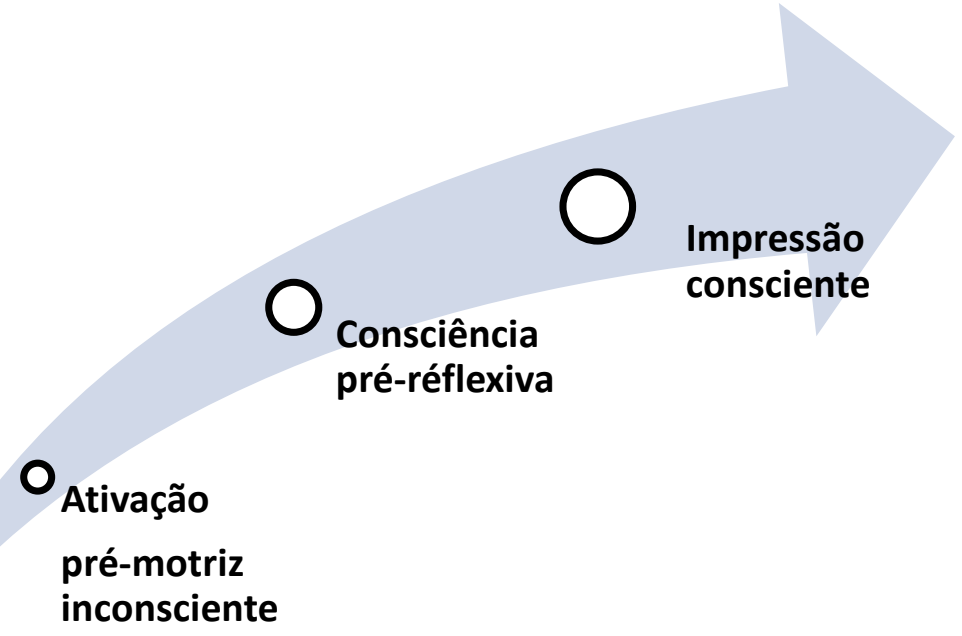

Figura 1: Continuidade emersiva e descontinuidade dos níveis de conhecimento (Andrieu \& Burel, 2013)

O obstáculo de um conhecimento do nosso corpo vivo, já estabelecido pela fenomenologia do corpo (Nóbrega, 2010), é principalmente a consciência do corpo vivido que coloca um véu perceptivo sobre as informações sensoriais e emocionais. O que nós tomamos por corpo vivo é uma percepção do corpo vivido. Como então distinguir o que provém diretamente do corpo vivo de sua percepção pelo corpo vivido:

- O tempo da informação se efetua acima de 450 ms enquanto no cérebro a ressonância se desencadeia de maneira mais rápida a partir de $40 \mathrm{~ms}$.

- O surgimento de uma informação que nos toma como a síncope (Clément, 1989), o orgasmo (Andrieu, 2013), o medo, a vertigem (Andrieu, 2014), a dor modificando o estado da consciência sob a influência do corpo vivo.

- O atraso com o qual a consciência do corpo vivido reconstitui uma narrativa e torna imperceptível o que faz o corpo vivo: sem nos darmos conta o corpo vivo realiza gestos e decisões que o adaptam as modificações do ambiente. 
- O desmaio, a inconsciência, a cegueira psíquica que manifestam a perda de controle pela fúria fisiológica.

- A dificuldade a retomar seus espíritos (sua calma, tranquilidade, equilíbrio) o vivido do corpo prório em razão das perturbações sensoriais e das ilusões corporais de sai de si ou da invasão de si .

Assim se apresenta a fenomenologia da percepção consciente. O problema vem do fato de que não estamos em direto com nossas sensações. Essas são ativadas em nosso corpo sem que nos demos conta. Há um atraso antes advenha a nossa consciência sensorial, um atraso variável entre 350 e 500 mil segundos (Libet, 2012; Andrieu, 1998). A sensação nos surpreende do interior sem que possamos alcançar nem sua intensidade, nem sua direção. O que nós percebemos em 1ạ pessoa, na narrativa fenomenológica, já é uma deformação perceptiva do conteúdo que emerge inconscientemente desde o nosso cérebro e sistema nervoso. Essa deformação subjetiva na narrativa consciente provém do atraso de transmissão da informação produzida em nosso corpo até à consciência. Esse filtro da consciência muda a qualidade e intensidade da sensação primeira que surgiu no corpo.

Assim, quando a sensação de prazer ou de dor chega à consciência, eu consigo senti-la apenas em atraso ao êxtase vivo (espasmo, orgasmo) desencadeado em mim. A percepção consciente efetiva para mim ocorre $500 \mathrm{~ms}$ após o que foi ativado em mim. Eu estou em atraso sobre o que se passa em meu corpo vivo. Eu devo compor minha motricidade a partir de um filtro perceptivo. Esse atraso nos tentamos diminuir por técnicas e práticas corporais, diminuindo-se a atenção e a vigilância usando drogas, corpos, álcool. Assim, acreditamos poder comunicar diretamente pela linguagem corporal o que é ativo em nós.

O sujeito pode, no momento da consciência do seu êxtase, antedatar a origem da sensação que o atravessa? Ele pode encontrar o momento do desencadeamento sensorial desde que sua efetivação se efetua antes mesmo que ele seja consciente? Se é necessário 500ms de atividade cerebral para que a sensação alcance a consciência, eu gozo ou eu sofro após um tempo mais longo e que desconheço. Meu corpo goza e sofre antes mesmo de mim e sem mim.

\section{UM CORPO VIVO IMERSO}

O corpo vivo se imerge nos espaços, inserindo-se inteiramente nos espaços no curso da imersão sem que uma personalidade dirija conscientemente esses movimentos. Convém evitar aqui um vitalismo finalista que atribuiria uma intencionalidade representacional do corpo vivo. Uma ecologia pré-motriz é sentida imediatamente pelo corpo na relação com o mundo. O corpo vivo age em pessoa e não como uma pessoa, sem intermediário, menos por uma reflexividade consciente que por um despertar e uma ativação. Na imersão, o corpo vivo invade inteiramente a sensibilidade sem que o sujeito consiga ser extraído pela reflexão: a intensidade é tão forte que ela transborda os quadros estesiológicos habituais, emergindo na consciência do corpo vivido. 
Quadro 1: O espaço global da consciência

O corpo objetivado por uma 3a pessoa (Corpo objetivo)

(Meta)CONSCIÊNCIA REFLEXÃO Cogito Autoconsciência

O corpo vivido em 1a pessoa (Imagem do corpo subjetivo) SUB-CONSCIÊNCIA ----------EMERSÂO por ATIVAÇÃO

O corpo vivo em pessoa (Esquema corporal in vivo)

IN-CONSCIÊNCIA INSERÇÃO nas experiências

Ecologia do corpo inteiro/todo

Para sentir nossas sensações em sua vida e a possibilidade de se imergir mais diretamente na vida por um contato imediato engaja nosso corpo no mundo. Esse contato imediato torna-se possível, nós sabemos a partir dos recentes trabalhos sobre as neurociências in vivo, definindo assim uma nova compreensão da sensibilidade corporal, uma osmose sentida desde o interior sensitivo de nosso corpo até as coisas do mundo exterior. Essa fusão intuitiva é uma osmose somática pela produção em si de sensações internas: nosso corpo vivo sente o mundo, antes que tenhamos consciência do que nomeamos até aqui com a fenomenologia do corpo vivido.

Mas, essa osmose somática repousa sobre dois princípios que aqui descrevemos: de uma parte a emersão por ativação em si de potenciais evocados pela interação de nossa sensibilidade com o mundo exterior; de outra parte a ecologização espontânea das sensações desde o nosso corpo vivo pelo efeito dessa ecologização abaixo do nosso limiar de consciência: "A consciência desempenha um papel preeminente na resolução das ambiguidades perceptivas » (Dehaene, 2014, 138).

Assim, avivada pelo embarque e incorporação (embodiment) em um novo imersante, o vivo ativa em nosso corpo uma sensação da qual temos apenas uma consciência com um atraso. Com efeito, a ativação, entre $40 \mathrm{~ms}$ e $450 \mathrm{~ms}$ antes do limiar da consciência, antecipa por sua ecologização imediata a resposta adaptativa do corpo: um tempo mais imediato alimenta essa percepção direta, fornecendo uma sensação de osmose de nosso corpo no mundo. Assim a vertigem precipita em nós uma sensação irredutível contra a qual nossa consciência nada pode.

A corporeidade motriz encontraria com o sentido do esforço desde Maine de Biran, uma experiência para descobrir esse corpo próprio (propréité). O corpo vivo é conhecido pelo sujeito somente pelo que depassa as informações sensoriais que alcançam a consciência: " o corpo não é conhecido pelo sujeito, mas compreende-o sem se identificar com ele. Nada mais que o que se manifesta no interior do sujeito existente como pulsão ou esforço, como o que resiste a esse esforço" (Barbaras, 2011, 139).

Haveria na experiência corporal uma verdade que não mente. O corpo não mentiria. Ele falaria dele sem que tivessemos consciência. O que escapa de meu corpo são esses signos que observamos do exterior, mas que são gestos, posturas e técnicas que animam a vida do nosso corpo. O corpo vivo já se encontra em ato (Berthoz; Andrieu, 2011).

A estratégia do corpo vivo é a de adaptar o corpo vivido o mais imediatamente à ação. Essa estratégia não é intencional para a consciência que não a possui. A sensibilidade intuitiva é subconsciente, resultado da ecologia premotriz incorpora-se no habitus. Essa sensibilidade é 
orientada por esquemas sensoriais elaborados no curso da experiência e que fornece esse caráter intuitivo e espontâneo ao gesto da ação. Em mutação por adaptação informacional, o corpo vivo planeja, à nossa revelia, uma saúde precária e uma homeostase em desequílibrio que nos força a nos reorganizar.

Colocar-se na escola do corpo vivo é aceitar ser ensinado por ele e não controlá-lo absolutamente. O corpo vivo nos leva à escola de sua mutação, de sua ecologização e seu dinamismo. Ele encontra soluções afetivas e motrizes independente de nossa decisão consciente. Nossa capacidade de adaptação nos é desconhecida, pois a consciência de nosso corpo vivido mantem uma imagem cuja representação de si é suficiente para nos conter.

Ora a modificação das condições biológicas do corpo vivo é imperceptível até que a consciência perceba os signos emersivos por meio da sensibilidade. O corpo vivo, como organismo conectado ao mundo por seu sistema neurosensorial, o que chamamos "o mundo corporal"(Andrieu, 2010) cuja usabilidade - affordances (Gibson, 2014), produz uma informação autoregulada e permanente que é produzida mesmo quando a consciência do corpo vivido está adormecida, em vigília, quando do sono ou dos gestos habituais automáticos que realizamos sem nos darmos conta.

Esse saber sem conhecimento e vivo em meu corpo é aquele de meu corpo ou aquele de minha cultura? Estabelecer uma continuidade entre os diferentes níveis suporia uma homogeneidade dos três niveis do corpo em uma só unidade corpo-espírito.

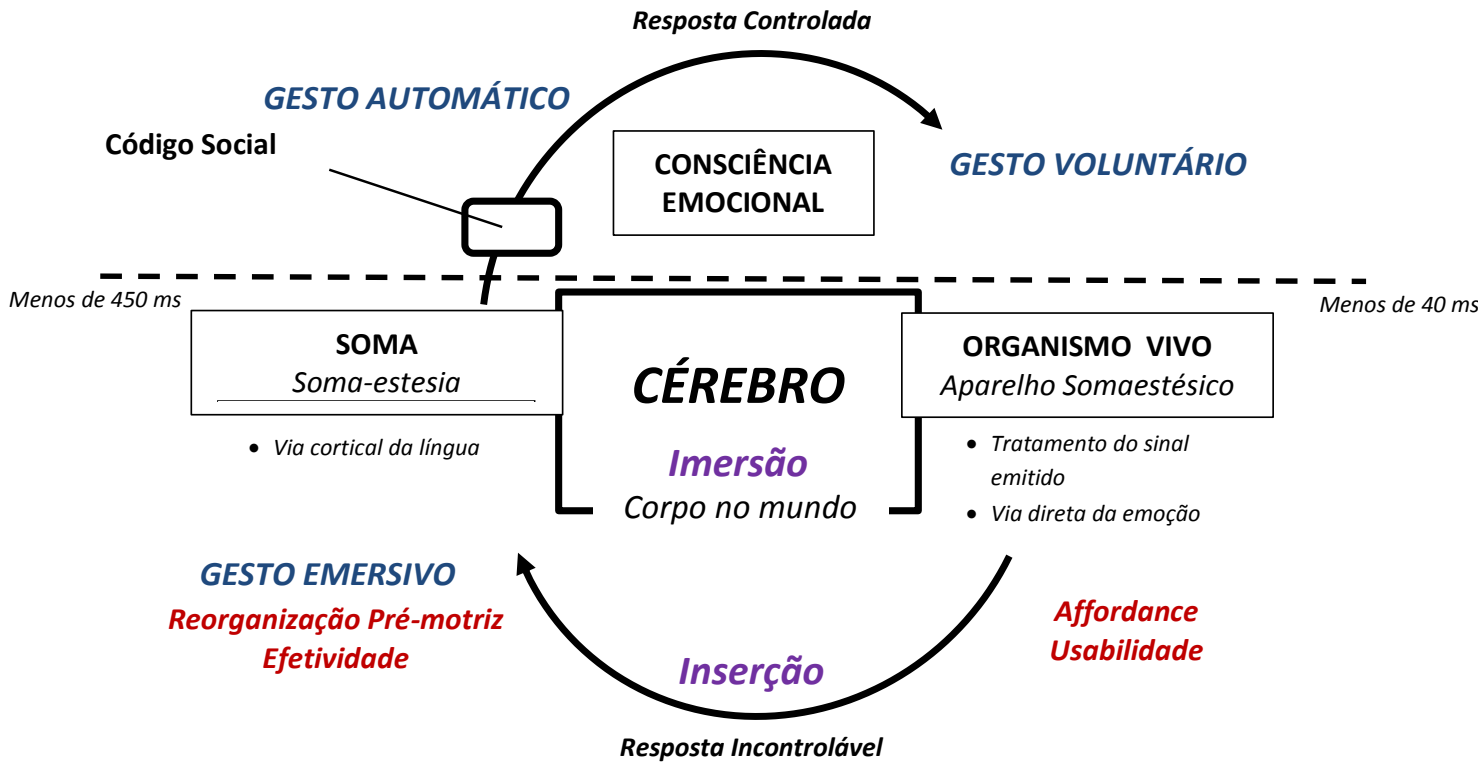

Figura 2: Emersão cognitiva em 1ạ pessoa do corpo vivo (Andrieu \& Burel, 2013)

A emersiologia é uma ciência reflexiva nascida da emersão dos sensíveis provindos de nosso corpo vivo na consciência do corpo vivido. Essa percepção fenomenológica que define o corpo vivido como uma imagem do corpo é qualitativamente menos intensa que o vivo do esquema corporal imerso no corpo dessas experiências sensíveis. A emersão, diferentemente da enação (énaction) de Francisco Varela que visa a ser apreendida pela consciência, é o movimento involuntário em nosso corpo de redes, humores e imagens as quais nossa consciência conhece apenas a parte emergida. O corpo vivo produz sensíveis pela sua ecologização com o mundo e com 
os outros. Mas, em razão do tempo da transmissão nervosa, 450ms até à consciência do corpo vivido, o corpo vivo é conhecido - Herbert Feigl o descreve em l'impossible autocérébroscopie, desde 1958 - somente em atraso pela consciência do corpo vivido

Prestar atenção ao vivo em nós é aguardar um sinal, uma informação suficientemente inabitual e inédita para nos surpreender. A porosidade do corpo vivo, conforme o filme Planète corps (planeta Corpo) ${ }^{1}$, é aquela de um ecossistema em equilíbrio dinâmico no qual o todo deve sua forma ao movimento das partes que o compõem. O vivo do corpo se exprime espontaneamente sem o controle do sujeito consciente: essa ecologização é uma regulação. Para Nathalie Depraz, na terceira fase da atenção, " passamos a uma disposição ao acolhimento que é um deixar vir (...) [que mantém] uma tensão entre um ato de atenção sustentado e um não preenchimento imediato...há uma espera sem consciência do conteúdo que vai se revelar " (Depraz, 2014, 43).

Essa espera é um acolhimento que é despertado a partir do interior do corpo vivo. Essa sensação é interna e involuntária mas vem preencher um conteúdo de consciência tão distante que uma representação não vem antecipá-la: « Sentimos a forma emergir até o ponto da mudança brutal da percepção» (Depraz, 2014, 43). Esse ajustamento da estrutura se distingue de um ajustamento ao conteúdo deixando recesso nossa capacidade a preencher nossa consciência do que vem do corpo vivo. O vivo surge em que façamos atenção, ele se impõe a nós pela informação que ele mesmo produz pois não temos o controle da intensidade sensorial: "a consciência reflexiva não pode controlar as condições da dinâmica atentiva por sua efetuação nem o conteúdo» (Depraz, 2014, 44).

$\mathrm{O}$ acesso ao corpo vivo é duplo. A emersiologia tem um duplo movimento. Ela reconhece na consciência do corpo vivido as informações afetivas e pré-motrizes que foram ativadas pelo corpo vivo quando de sua ecologização. A emersão é aqui um despertar da consciência pelos movimentos involuntários, os impulsos reflevivos e as emoções diretas.

- Seja a partir do aprofundamento da consciência que favorece a atenção (Depraz 2014, PetitMengin, 2001) aos estados interiorse e íntimos por técnicas de meditação, de concentração como a yoga.

- Seja a partir do despertar (Sacks, 1973) ou ativação no corpo vivo das informações neuro-inconscientes (Dehaene 2014) que remontam a superfície da clara consciência involuntária.

\section{CONCLUSÃO}

Os traços da atividade do vivo vem ultrapassar o controle consciente de seu corpo vivido, como Freud colocou o modelo emersivo do involuntário não intencional na Pychopathologie de la vie quotidienne através do conceito de ato falho. Como mostramos para o orgasmo (Andrieu, 2013) e a vertigem (Andrieu 2014), o medo da perda do controle; abandonando-se a uma informação surpreendente ao mesmo tempo psicológica e física.

Esse transbordamento é fundado sobre:

\footnotetext{
${ }^{1}$ http://www.monalisa-prod.com/vf/production.php?id=66
} 
- A atividade biológica e química do organismo que produz os humores, da vertigem ou da dor.

- O quadro insuficiente da sensibilidade consciente que é culturalmente constrangedora conforme os ritos de interação (Goffman, 1974).

- A pesquisa do dispositivo de invasão das sensações do vivo no corpo vivido, colocandose em estados de êxtase com o LSD como Timothy Leary (Penner, 2014) ou em rituais de iniciação (Flahutez; Egana, 2014) como Marion Laval-Jeantet relata.

- A sensibilidade nova à percepção de seu próprio corpo (Vigarello, 2014) é uma experiência de sensações internas que convém circunscrever e conhecer para descobrir a profundidade de seu corpo.

O traço desse transbordamento está inscrito no corpo vivo sem que para tanto o corpo vivido tenha dele uma consciência clara:

- O traço pode ser crônico como na ferida ou na doença que mantém uma sensação que emerge de maneira lancinante na consciência do corpo vivido.

- O traço pode ser traumatizante (Scarry, 1988) no caso de um estrupo, de uma tortura, de uma violência psicológica, de sequelas de uma doença que vem alterar a saúde física do corpo vivo em uma manifestação psicossomática (Winnicott, 2014) ou um estado psíquico degradado em razão da regulação dos afetos.

- O traço pode ser retentivo o qual perdura apesar da perda da sensação real através da imagem que se destaca e volta na via imaginária e psíquica.

O traço é pois emersivo de três maneiras:

- Seja revivendo a sensação incorporada no vivo como um engrama que ressurge por uma emersão, como uma cápsula que se libertaria através de todo o corpo.

- Seja despertando por um estímulo exógeno forte que sai de seu sono ou de sua não especialização, como nas células-tronco, um traço físico ou psíquico que ainda não teria sido atualizado.

- Seja despertando-no pela criação na profundidade do corpo novas redes neuronais e novas sensibilidades imergindo-se em experiências inéditas.

O acesso a seu corpo vivo e a seu cérebro in-vivo renova assim a percepção de si em uma interação ecológica (Sirost; Andrieu, 2014) com o mundo e com os outros. O corpo vivo nos fornece as informações objetivas sobre o mundo no qual nossa percepção nos dá um conhecimento parcial, mas subjetivamente intenso.

\section{REFERÊNCIAS BIBLIOGRÁFICAS}

1. ANDRIEU, Bernard. Le corps dispersé. Une histoire du corps au XXe siècle. Paris, L'harmattan, Reed, 1996 et 2000.

2. . 1998, La neurophilosophie. Paris: PUF, Reed 2007.

3. A N N N Filosofia do Corpo. Lisboa: Instituto Piaget, 2004.

4. H. Feigl, de la physique au mental. Paris: Vrin. Préf Pr. G. Heinzmann, Dir Archives Poincaré. Avec M. Heidelberger, S. Laugier, A. Metraux, L. Soler, J.C. Dupont, J.N. Missa. 2006 
5. d'Homme: 2011.

6.

(ed.). Le corps du chercheur. Une méthodologie immersive. Nancy: Presses Universitaires de Nancy, 2011. (Collection Epistémologie du corps.)

7. Sentir son corps en première personne : une écologie pré-motrice, Mouvement \& Sports Sciences - Sciences \& Motricité, 2013, 81 : 91-99, 2013.

8. La peur de l'orgasme. Dijon: Ed Le murmure, 2013.

9. Donner le vertige. Les arts immersifs, Montréal: Liber, 2014.

10. Sentir son cerveau. Une méthode émersive. Tome 1 de L'Emersiologie. Paris: L'harmattan, 2015.

11. BUREL, N.. La communication directe du corps vivant: une émersiologie en première personne, Hermes, n68/1, p.46-52, 2014.

12. ; FELIX, F. (Orgs.). Quel Physicalisme? Carnap, Schlick, Popper, Feigl. Lausanne: Ed l'Age d'Homme, 2013.

13. ; RICHARD, G. (Orgs.). L'expérience corporelle en Staps, Staps, n98, 2012.

14. ; BUREL, N.; PAINTENDRE, A. (Orgs.). Un corps pour enseigner, Paris: Lharmattan, 2015.

15. BARBARAS, Renaud. L'ouverture du monde: Lecture de Jan Patočka. Editions de la Transparence: 2011.

16. BERTHOZ, A.. La vicariance. Paris: O. Jacob, 2013.

17. ; ANDRIEU, Bernard (Orgs.). Le corps en acte: Centenaire Maurice Merleau-Ponty. Lorraine : P.U. de Lorraine, 2008. Coll. Epistémologie du Corps.

18. CARNAP, R. Logique et Physicalisme. Essais 1934-1952. Lausanne: Ed L'Âge d'Homme, 2011.

19. CLÉMENT, C. La syncope; philosophie du ravissement. Paris: Grasset, 1994.

20. DEHAENE, S. Le code de la conscience. Paris: O. Jacob, 2014.

21. DEPRAZ, Natalie. Attention et vigilance. A la croisée de la phénoménologie et des sciences cognitive. Paris: P.U.F., 2014.

22. FEIGL, H. Le mental et le physique [1958. 1967]. Paris: L'Harmattan, Université de Minneapolis avec Christine Lafon. 2002.

23. FLAHUTEZ, Egana (Org.). Arts drogués: Expériences psychotropiques et création artistique. Paris: Presses Universitaires de Paris X, 2014.

24. GIBSON J.J. L'approche écologique de la perception visuelle. Éditions Dehors, 2014.

25. GOFFMAN, E. Les rites d'interaction. Paris: Minuit, 1974.

26. JEANNEROD, M. Le cerveau volontaire. Paris: O. Jacob, 2009.

27. LIBET, B. L'esprit au-delà des neurones. Paris: Dervy, 2012.

28. NACCACHE, L. De quoi prenons-nous conscience. Paris: Editions Manucius, 2013.

29. NÓBREGA, Terezinha Petrucia. Uma Fenomenologia do Corpo. São Paulo: Editora Livraria da Física, 2010. 
30. PENNER, J.; TIMOTHY, Leary. The Harvard Years: Early Writings on LSD and Psilocybin. Park Street Press, 2014.

31. PetitMENGIN, C. L'expérience intuitive. Paris: L'Harmattan, 2001.

32. QUIDU, M. (Org.). L'épistémologie du corps du savant. 2 tomes. Paris : L'Harmattan, 2014.

33. SACKS, O. L’éveil. Cinquante ans de sommeil. Paris: Le Seuil, 1973.

34. SCARRY, E. The Body in Pain: The Making and Unmaking of the World. Oxford Paperbacks, 1988.

35. SIROST, O.; ANDRIEU, B. (Orgs). L'écologie corporelle, Sociétés, Nº spécial, 2014.

36. VANPOULLE, Y. Epistémologie du corps en Staps. Vers un nouveau paradigme. Paris: L'Harmattan, 2011. Coleção «Mouvements des Savoirs ». 